\title{
Impact of structured advance care planning program on patients' wish items and healthcare utilization
}

\author{
Kwok Ying Chan ${ }^{1}$, Ho Yan Chiu ${ }^{1}$, Desmond Y. H. Yap ${ }^{2}$, Cho Wing Li ${ }^{1}$, Terence Yip ${ }^{3}$, Kwok Wai Tsang ${ }^{1}$, \\ Wai On Tam ${ }^{4}$, Ho Yan Au ${ }^{1}$, Chi Yan Wong ${ }^{1}$, Man Lui Chan ${ }^{5}$, Mau Kwong Sham ${ }^{1}$ \\ ${ }^{1}$ Palliative Medical Unit, Grantham Hospital, Hong Kong, China; ${ }^{2}$ Division of Nephrology, Department of Medicine, Queen Mary Hospital, \\ University of Hong Kong, Hong Kong, China; ${ }^{3}$ Renal Unit, Tung Wah Hospital, Hong Kong, China; ${ }^{4}$ Tuberculosis and Chest Unit, Grantham \\ Hospital, Hong Kong, China; ${ }^{5}$ Kowloon Doctor Association, Hong Kong, China \\ Contributions: (I) Conception and study design: All authors; (II) Administration support: KY Chan, HY Chiu; (III) Provision of study materials or \\ patients: HY Chiu, KY Chan, T Yip, WO Tam; (IV) Collection and assembly of data: KY Chan, DYH Yap; (V) Data analysis and interpretation: \\ DYH Yap, KY Chan; (VI) Manuscript writing: All authors; (VII) Final approval of manuscript: All authors. \\ Correspondence to: Dr. Kwok Ying Chan, MRCP, FHKCP. Palliative Medical Unit, Grantham Hospital, 125 Wong Chuk Hang, Hong Kong, China. \\ Email: cky842@yahoo.com.hk.
}

Background: Structured advance care planning (ACP) program is an important service in the end-of-life care for patients with advanced medical illness. We pioneered a structured and coordinated ACP program for patients with advanced malignancies and end-stage organ failure in Hong Kong. This study investigated the impact of a structured ACP program on the concordance rate for patients' final wishes, patient/family satisfaction, and the number of acute admissions (AA) and length of stay (LOS) in hospital.

Methods: Patients with advanced malignancy or end-stage organ failure who were able to complete ACP forms during the current admission to medical units were recruited. Patients who could not complete ACP forms or $<18$ years of age were excluded. The ACP program comprised the following components: (I) baseline education (workshop/role play) in ACP sessions for linked nurses of different medical units; (II) structured ACP discussions with recruited patients and their proxies during admission, after any change in clinical status, and also at monthly intervals; (III) formal structured review of patients' goals at regular team meetings; (IV) "flagging" of advance directive (AD) in hospital computer system and (V) feedback to linked nurse on the congruence of care. Mentally competent patients who did not receive ACP and matched for disease and demographics were selected as controls in a 1:2.5 ratio.

Results: Two hundred forty-three patients were included for analysis between August 2016 and July 2017, of which 69 patients joined the ACP program and 174 of them did not. Two hundred and one patients $(83 \%)$ had advanced cancer. All had done do-not-attempt-cardiopulmonary-resuscitation (DNACPR) order in the ACP group. The concordance rates for patients' wishes on quality of life, end-of-life and funeral arrangements were $95 \%, 100 \%$ and $100 \%$ respectively. Over $70 \%$ of patients and their families $(\mathrm{N}=10)$ showed satisfaction with the program. The ACP group also had lower mean AA and shorter LOS $(0.78 \pm 0.23$ vs. $1.2 \pm 0.8$ episode/patient, $4.6 \pm 1.7$ vs. $7.5 \pm 2.5$ days, $\mathrm{P}=0.037$ and $\mathrm{P}=0.023$ respectively) in the last 3 months of life compared with the non-ACP group.

Conclusions: This ACP program achieved high concordance rate for patients' wish items and reduced healthcare utilization.

Keywords: Advance care planning; palliative care; healthcare cost

Submitted Mar 16, 2020. Accepted for publication Sep 18, 2020.

doi: 10.21037/apm-20-589

View this article at: http://dx.doi.org/10.21037/apm-20-589 


\section{Introduction}

It is well recognized that there can be considerable discrepancy between the end-of-life (EOL) care patients receive and their final wishes $(1,2)$. For instance, though most of the participants reported that they prefer to die at home, more than $70 \%$ had eventually died in hospital, where they received more invasive or inappropriate care than they would expect $(3,4)$. Thus, it seems that the focus of patient's management is still active curable treatment rather than respecting their wish at the EOL (5). In fact, some of the patients with metastatic or terminal condition have not discussed their EOL care preferences with their in-charge physician, so they might suffer pain or discomfort from unnecessary interventions $(6,7)$.

Advance care planning (ACP) discussion is a useful way of enhancing EOL care with better arrangement and provision of the patients' care that meet their needs and preferences. ACP discussions are important conversations that can affect our practice as well as empower our patients. ACP discussion usually requires a period of time to make certain decisions (e.g., dialysis treatment) for the patients. People involved with provision of palliative and EOL care could play an important role in the ACP discussion, though staff with additional training will have advantage on facilitating the discussion (8).

Patients could express their expectations on the type of care they expect to receive at the EOL by using the advance statement in the ACP, which could have decisions/refusals of particular medical care, especially cardiopulmonary resuscitation and some aggressive treatments (8). The process of ACP can be useful in clarifying patients' wishes and preferences, in anticipation of possible future decline and mental incapacity. For those advanced cancer or endstage organ failure patients opted for conservative care, this will make sure that their expectations for EOL care can be respected. Professionals cared for these medically ill patients can be difficult to ascertain their wishes and preferences especially for those without family (9). There could be a chance that their clinicians are not willing to make advanced decisions, thus conflicts among different parties might arise. According to literatures, most medical staff are well aware of the unnecessary conflicts and invasive interventions in hospital setting when these patients reach EOL and become confused, distressed and powerless in the last 48 hours of life because there is a lack of documentation of his/her wishes, expectations or resuscitation status (9). One randomized controlled trial demonstrated that patients in the ACP group had higher likelihood of EOL wishes being known and followed, and their family members also reported less anxious or depressed (10). In addition, a systemic review showed that ACP could help improve the patient and family satisfaction during the process of medical care (11).

Due to the socio-cultural differences, the implementation of ACP remains difficult in the EOL care for local Chinese patients with advanced medical illness $(12,13)$. In this context, there is social taboo to discuss ACP in elderly Chinese patients. In addition, a significant number of patients with advanced medical illness are not aware of ACP including $\mathrm{AD}$ and most health professionals might not be competent enough to explain and discuss the wishes of those patients facing their EOL. With increasing westernization of the society, there is a growing demand for ACP and thus a service gap in the local population. Based on these backgrounds, our palliative care unit launched a hospitalbased structured ACP program across different medical specialties with the aim to improve the ACP training and implementation. This study reports the impact of this structured ACP program on concordance to patient's final wishes, patient and family satisfaction and also healthcare utilization in the local Chinese population.

We present the following article in accordance with the STROBE reporting checklist (available at http://dx.doi. org/10.21037/apm-20-589).

\section{Methods}

\section{Patients}

We retrospectively reviewed all patients who were referred to our unit for palliative care between August 2016 and July 2017. Patients with advanced medical illness and participated in the structured ACP program were included for analysis. For comparison, mentally competent patients who did not receive ACP and matched for disease status (underlying disease and date of referral) and demographics (age and sex) were selected in a $1: 2.5$ ratio as Controls.

\section{The ACP program}

This structural ACP program involved a coordinator, who was a trained nurse facilitator in Hong Kong West cluster (HKWC). The facilitator received training from Respecting Choices (RC) (14) which is a well-recognized international 


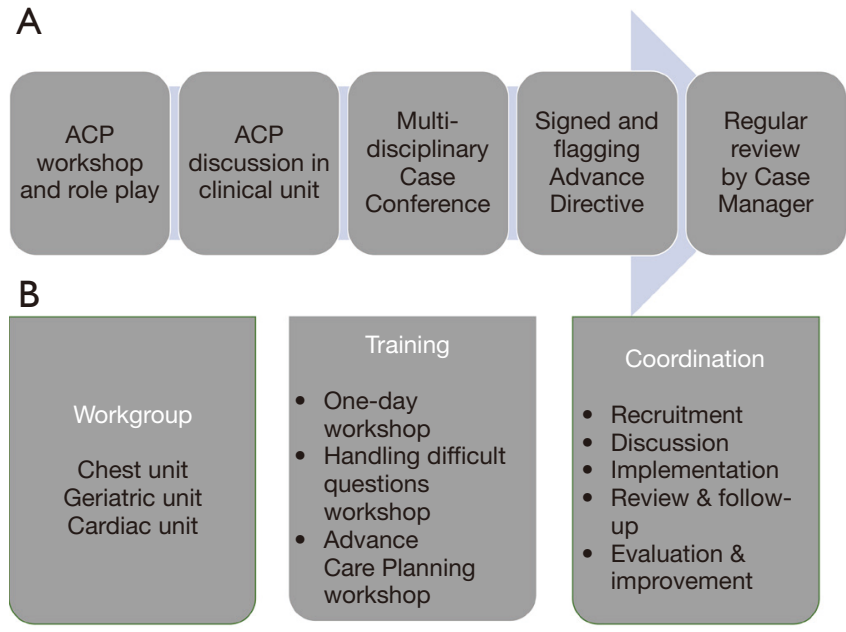

Figure 1 The essential components (A) and different phases (B) of the Advanced Care Planning program.

ACP program that provides certification to those having certain standards and competence in ACP communications after training. This program includes standard interview and conversation tools that help to engage the participants undergoing the process of ACP, explore their values, identify an appropriate healthcare decision maker, and also communicate the preferences for EOL care with healthcare staff.

\section{Implementation of the ACP program}

The process of developing the structural ACP program began in June 2016. A hospitalized-based committee of the ACP working group was organized (Figure 1). The working group established the following fundamental criteria for the program: (I) patient-centered, (II) based on existing international ACP program, (III) representatives from different departments and (IV) in line with the direction of care of those advanced medical illness with palliative care needs in HKWC. Members of the working group were selected according to the following criteria: (I) professional experience and (II) management executive for operation and logistics of the working of structural ACP program. All of the selected professionals were invited to participate in the working groups and to attend the official presentation of the program with the aims fully presented.

Before implementation of the ACP program, a classroom-based training (one-day workshop) was given to the medical and nursing staff in different units. ACP is usually regarded as necessary and useful, however it requires proper training and more detailed explanation of the implementation process. The concerns of those involved in the ACP implementation would be addressed during the training program. Diverse models of integrated palliative care were described and several different ideas on how to develop a comprehensive palliative care approach were presented in Hong Kong Medical Forum as well as the Hospital Authority Convention $(15,16)$.

Every medical unit which participated in this structured ACP program followed a standardized workflow targeted for ACP activities in the inpatient, outpatient, and ambulatory care settings (Figure 2). An educational brochure on ACP was provided to each participant. Participants were then asked if they have any type of ACP form. The purpose was to introduce the participant to the ACP topic and try not to overburden him/her with such a sensitive issue. For those patients who agreed to join, a consult was then arranged with the nurse facilitator. Those declined to meet would have a documentation with the reason in the medical progress note.

\section{Recruitment}

Participants were recruited from the different medical units (geriatric, respiratory cardiac and palliative units) of Grantham Hospital which is one of the major palliative care service providers in Hong Kong. To be eligible to participate, patients were required to meet selection criteria for advanced medical illness (both cancer and noncancer) patients based on Gold Standards Framework (17). Other criteria for inclusion were: (I) patient had decision making capacity; (II) patient could have a close family member as a witness for the patient ACP documentation and this family member was able to read, write, and speak Cantonese as his or her primary language; and (III) patient was older than 18 and was able to read, write, and speak Cantonese as his or her primary language. Of 71 eligible pairs of patients and their surrogates, 69 pairs agreed to join in this study. Reasons for refusal from 2 pairs were as follows: one patient did not want to talk about ACP and one family member of another patient did not want to participate.

\section{Role of facilitator and linked nurses in different units}

The trained nurse facilitator, collaborated with clinicians, 


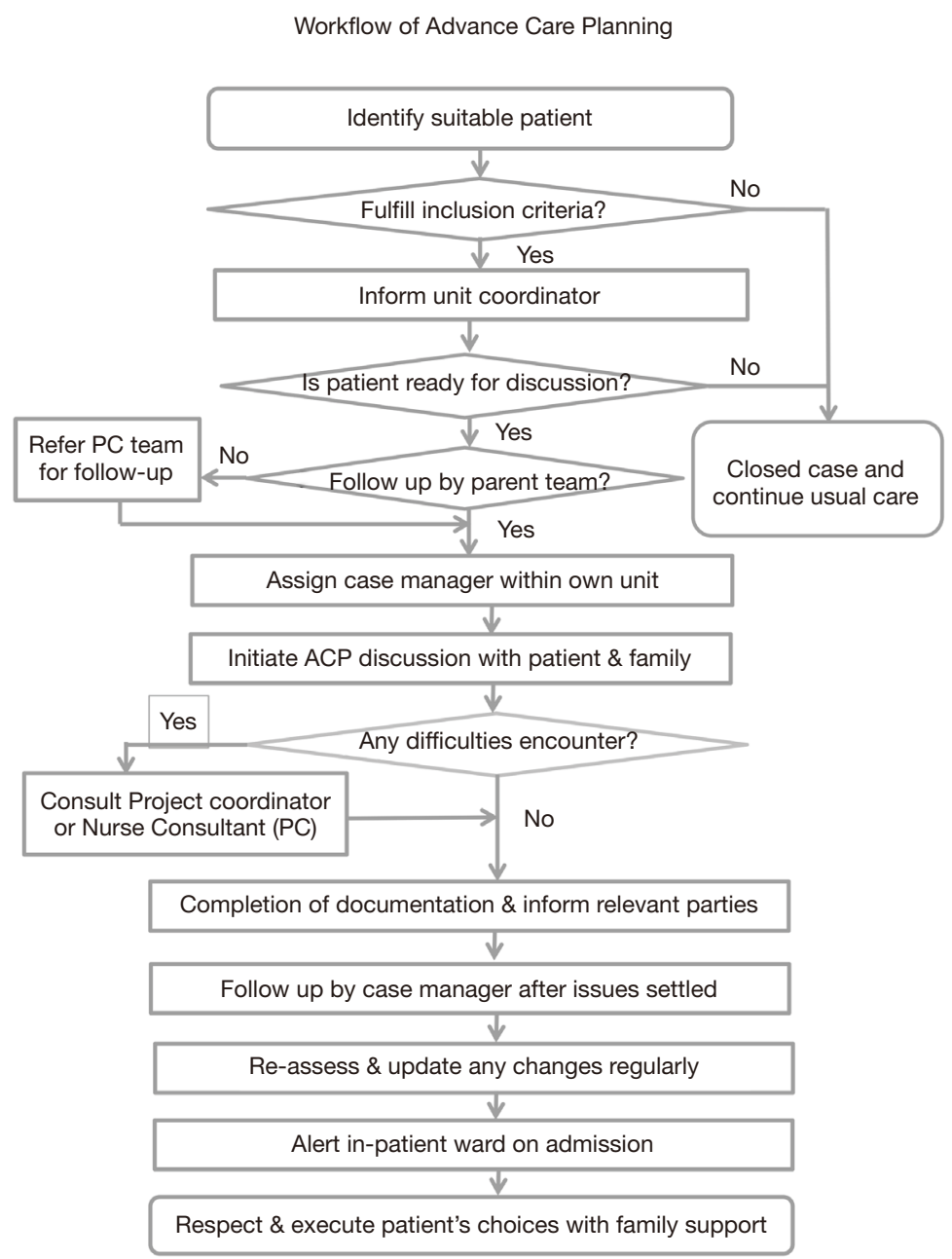

Figure 2 Workflow of the Structured Advance Care Planning (ACP) Program.

would help patients and their families in reflecting on the patients' goals, values and expectations and also discuss their healthcare wishes (10). The communication also enhanced patients to identify particular issues or things which might improve or worsen their care during EOL. The participants were also urged to nominate a close relative and to have documentation about the care they would expect to obtain in medical and non-medical (including funeral, caring) aspects. Their wishes on refusal of burdensome lifeprolonging interventions such as chemotherapy or other aggressive interventions would be discussed. The nurse facilitator would deliver the training program to the linked nurses of different units. The roles of the linked nurse were to refer suitable patients to the ACP program and work as the coordinator for the patient care of his/her own unit.

\section{Assessment and data collection}

At baseline, in personal structured interviews, the facilitator would assess patients' disease understanding and their skills related to daily living. Patient demographic data would be collected from electronic healthcare data record. At each month follow-up, participants were interviewed again and their competence would be assessed. Patients and their relative were asked about their feedback on our program. We also analysed the medical care which participants receive every month after recruitment, such as invasive procedures and hospitalizations [number of episodes, length of stay (LOS)]. The concordance of each wish item was found by contact with main family caregiver and from the electronic case record 3 months after patient death. The end-of-life care received was either in accordance/discordance with 
patient's wish.

\section{Study outcomes and statistical analyses}

The primary objective was to study the outcomes of the structural ACP program on the concordance of wish items (quality of life, EOL care, dying process and funeral arrangement) (Figure 3) and patient/family satisfaction (Table 1). The secondary outcomes were healthcare utilization including episodes of acute admissions (AA) per patient and LOS in hospital. Continuous variables were expressed as mean (SD) or median (range) and analyzed with $t$-test (paired or unpaired), Mann-Whitney test or ANOVA where appropriate. Categorical variables were expressed as frequencies (percentages) and analyzed with Chi-square test or Fisher-Exact test where appropriate. Rate of AA and average LOS for each patient, that were calculated by the number of episode(s) over a three-month period at the end of life, were compared between ACP and non-ACP groups using independent $t$-tests. Statistical significance was inferred by a two-tailed $\mathrm{P}$ value of 0.05 or less. Analyses were performed using SPSS, version 22.0 (SPSS, Inc., Chicago, IL, USA).

Written informed consent was obtained from all participants. They were permitted to withdraw from the study at any time without negative consequences. The study was conducted in accordance with the Declaration of Helsinki (as revised in 2013). Ethical approval for this study was issued by the Institutional Review Board of the University of Hong Kong and Hospital Authority Hong Kong West Cluster (HKWC) (No. UW 16-370).

\section{Results}

\section{Patient characteristics}

Two hundred and forty-three patients were included for analysis, of which 69 and 174 patients have or have not participated in the ACP program (Table 2). Two hundred and one patients $(83 \%)$ had advanced cancer as primary diagnosis. All patients in the ACP had do-not-attemptcardiopulmonary-resuscitation (DNACPR) order. Mean age (SD) of ACP group and non-ACP groups were 58.8 [13] and 60.4 [16] years old respectively, and approximately $46-47 \%$ were men in both groups. The median of the number of sessions to achieve ACP was 4.3 (range, 2-7 sessions). After 6 months of recruitment, 62 (90\%) patients of ACP group died while all patients in control group have succumbed.

\section{Compliance rate for wish items and survey of the program}

The concordance rate for wish item was defined as the number of items achieved per total items after death. The overall concordance rate to patients' final wishes/ preferences was $98.1 \%$ in the ACP group. The concordance rates for patients' wishes on quality of life, end-of-life care and dying process were $95 \%, 100 \%$ and $94 \%$ respectively (Figure 4). Our survey showed $70 \%$ of the patients and families strongly agreed that the ACP program would help to understand the needs and the things to address EOL care of patients in items $7 \& 8$ (Table 1).

\section{Impact on bealthcare utilization}

Fifty-four and 209 episodes of unscheduled AA occurred in the ACP and non-ACP groups respectively. The reasons for the unscheduled AA included infection (52\%), symptom control (37\%) in ACP group while symptom control and infection accounted for $47 \%$ and $45 \%$ of total AAs in nonACP group. The ACP group also had significant less AA and shorter LOS, $(0.78 \pm 0.23$ vs. $1.2 \pm 0.8$ episode/patient, $4.6 \pm 1.7$ vs. $7.5 \pm 2.5$ days, $\mathrm{P}=0.037$ and $\mathrm{P}=0.023$ respectively) in the last 3 months of life when compared with Control group (Figure 4).

\section{Discussion}

We began to develop a structured ACP program in 2016, as part of a broader process care for patients with advanced cancer and end-organ failure opted for conservative treatment. The ACP project adopted international recommendations for successful ACP implementation, taking into consideration the need to incorporate ACP within the existing model of care framework, which already included health policies that defined ACP as central to the model (14).

Our current results showed that a structured ACP program could achieve high concordance for patients' final wishes and patient/family satisfaction, and also reduce AAs and the length of hospital stay. The high concordance rate of the wish items might be related to the good coordination among the facilitator, linked nurse and agreed workflow between parent and PC teams. Previous study showed patients with advanced cancer or organ failure would like the chance to get involved for EOL discussion and might 


\begin{tabular}{|c|c|c|c|}
\hline \multicolumn{4}{|c|}{$\begin{array}{c}\text { Grantham Hospital } \\
\text { Palliative Medical Unit }\end{array}$} \\
\hline Patient Name & : & Name of Facilitator (Staff) & . \\
\hline \multicolumn{2}{|c|}{ Name of relative (who join the discussion) \& relationship } & Date & . \\
\hline \multicolumn{4}{|c|}{ Patient's preference } \\
\hline \multirow{2}{*}{ Health Status } & \multicolumn{3}{|c|}{ Patient/ family* understood present health status and prognosis. } \\
\hline & \multicolumn{2}{|c|}{$\square$ Yes (Please refer to "More understanding"「了解多一點」 for details). } & $\square$ No \\
\hline \multirow{2}{*}{ Quality of life } & \multicolumn{3}{|l|}{ Patient's value has been shared with his/her family. } \\
\hline & \multicolumn{2}{|c|}{$\square$ Yes（Please refer to "More understanding" 「了解多一點」 for details） } & $\square$ No \\
\hline \multirow{2}{*}{ Preferable care } & \multicolumn{3}{|c|}{ Patient has expressed his/her wishes of preferable care in late stage of life. } \\
\hline & \multicolumn{2}{|c|}{ 口 Yes (Please refer to "More understanding" 「了解多一點」 for details) } & $\square$ No \\
\hline \multirow{7}{*}{$\begin{array}{l}\text { Preferable } \\
\text { treatment }\end{array}$} & \multicolumn{3}{|c|}{ What kind of life-sustaining treatment that you do not want to receive? } \\
\hline & Cardiopulmonary resuscitation & $\square$ Yes & $\square$ No \\
\hline & Invasive / Non-invasive artificial ventilation* & $\square$ Yes & $\square$ No \\
\hline & Hemodialysis / Peritoneal Dialysis* & $\square$ Yes & $\square$ No \\
\hline & Antibiotics & $\square$ Yes & $\square$ No \\
\hline & Intravenous / Subcutaneous infusion* & $\square$ Yes & $\square$ No \\
\hline & Artificial tube feeding & $\square$ Yes & $\square$ No \\
\hline \multirow{2}{*}{ Dying process } & \multicolumn{3}{|c|}{ Patient has expressed his/her wishes of preferable environment of dying. } \\
\hline & \multicolumn{2}{|c|}{ 口 Yes（Please refer to "More understanding” 「了解多一點」 for details） } & $\square$ No \\
\hline \multirow{2}{*}{$\begin{array}{c}\text { Funeral } \\
\text { arrangement }\end{array}$} & \multicolumn{3}{|c|}{ Patient' s wish about funereal arrangement is known to his/her family. } \\
\hline & \multicolumn{2}{|c|}{ 口 Yes (Please refer to "Môre understanding"「了解多一點」 for details) } & $\square$ No \\
\hline
\end{tabular}

\begin{tabular}{l|l|l}
\hline Name of contact person in emergency & Relationship & Contact number \\
\hline Name of surrogate & Relationship & Contact number \\
\hline
\end{tabular}

\begin{tabular}{l|l|l}
\hline 1. Name & Relationship & Contact rumber \\
\hline 2.Name & Relationship & Contact number \\
\hline
\end{tabular}

•Please delete the inappropriate

Figure 3 The sample of the Advanced Care Planning (ACP) form. 
Table 1 Patient and family satisfaction on the ACP Program

\begin{tabular}{|c|c|c|c|c|}
\hline Items & \multicolumn{2}{|c|}{ Patient } & \multicolumn{2}{|c|}{ Family } \\
\hline 1. Disease understanding & $40 \%$ & $60 \%$ & $40 \%$ & $60 \%$ \\
\hline 2. The patient progress & $40 \%$ & $60 \%$ & $40 \%$ & $60 \%$ \\
\hline 3. Patient's quality of life & $40 \%$ & $60 \%$ & $40 \%$ & $60 \%$ \\
\hline 5. Family care and assistance & $40 \%$ & $60 \%$ & $30 \%$ & $70 \%$ \\
\hline 6. Patient's chief complaints & $30 \%$ & $70 \%$ & $20 \%$ & $80 \%$ \\
\hline 7. Understand needs at QOL & $70 \%$ & $30 \%$ & $70 \%$ & $30 \%$ \\
\hline 8. Things to address end of life care & $70 \%$ & $30 \%$ & $70 \%$ & $30 \%$ \\
\hline
\end{tabular}

ACP, advanced care planning; QOL, quality of life; EOL, end of life.

Table 2 Demographics and clinical characteristics of patients who have or have not participated in ACP program

\begin{tabular}{|c|c|c|c|}
\hline Variables & $\operatorname{ACP}(n=69)$ & $\begin{array}{c}\text { Non-ACP } \\
(n=174)\end{array}$ & $P$ value \\
\hline \multicolumn{4}{|l|}{ Sex } \\
\hline Male & $32(46 \%)$ & $82(47 \%)$ & 0.76 \\
\hline Female & $37(54 \%)$ & $92(53 \%)$ & \\
\hline Age (SD) & $58.8 \pm 13$ & $60.4 \pm 16$ & 0.55 \\
\hline Type of cancer (n) & 57 & 144 & \\
\hline Colorectal & $21(37 \%)$ & $53(37 \%)$ & 0.93 \\
\hline Lung & $9(15 \%)$ & $23(16 \%)$ & 0.87 \\
\hline Gynecological & $6(11 \%)$ & $15(10 \%)$ & 0.82 \\
\hline Pancreas & $5(9 \%)$ & $13(9 \%)$ & 0.86 \\
\hline Cholangiocarcinoma & $3(5 \%)$ & $7(5 \%)$ & 0.78 \\
\hline Breast & $5(9 \%)$ & $13(9 \%)$ & 0.86 \\
\hline Prostate & $5(9 \%)$ & $13(9 \%)$ & 0.86 \\
\hline Hematology ${ }^{\#}$ & $3(5 \%)$ & $7(5 \%)$ & 0.78 \\
\hline $\begin{array}{l}\text { Non-cancer diagnosis } \\
\text { (n) }\end{array}$ & 12 & 30 & \\
\hline Renal failure & $9(75 \%)$ & $23(76 \%)$ & 0.87 \\
\hline COPD & $2(17 \%)$ & $4(14 \%)$ & 0.57 \\
\hline Heart failure & $1(8 \%)$ & $3(10 \%)$ & 0.43 \\
\hline Median survival (days) & 57 & 63 & 0.66 \\
\hline
\end{tabular}

require several sessions to complete their ACP (3). In this cohort, patients required approximately four sessions to reach ACP decision.

While previous studies showed inconclusive results for overall health utilization at the EOL in other RC programs (18), our present data revealed that a structured ACP program could significantly reduce the rate of AA and LOS in the local Chinese population. The reduction in AA might be explained by the fact that many participants who joined ACP had more time to discuss the place and interventions received at the end of life, which resulted in better psychological preparation to face death and also more preference to die in a hospice setting. Furthermore, patients and their caregivers can consult the linked nurse in case of increased symptoms and thus can enhance their confidence to be nursed at home and reduce the number of AA.

One unique feature of our program was the integration of ACP into patients from different medical subspecialties (geriatric, cardiac and pulmonary), which was in line with the hospital strategy to increase coverage of palliative care in medical units. Our ACP program also emphasized on a multi-disciplinary approach and collaboration between the patients' parent team and also the palliative care specialists. The RC program, one of the outstanding international programs, is a good example to illustrate how an ACP can be incorporated into the healthcare system (14). The reason for its success might be related to the presence of the facilitator who is an important person in our ACP 
A

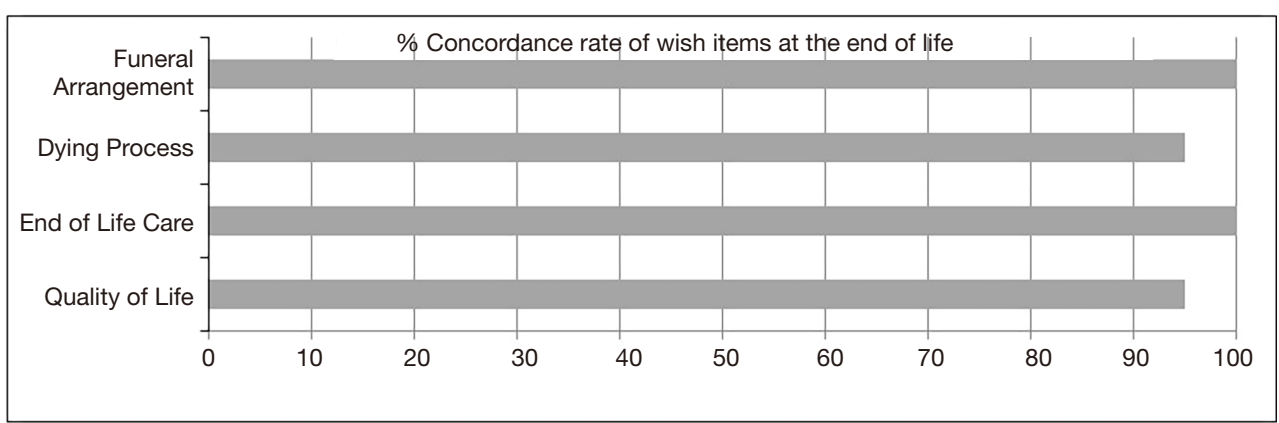

B

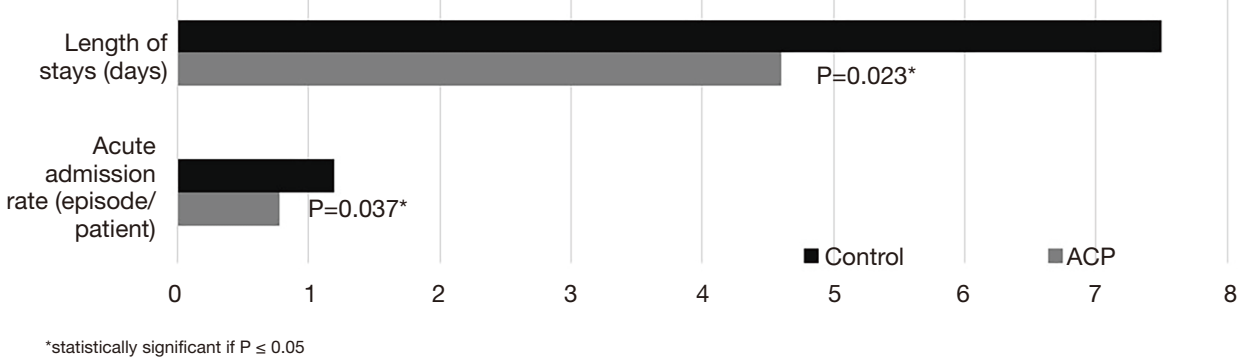

Figure 4 Impact of the ACP program on the (A) Concordance rates of patients' wishes and (B) health care utilization in patients with advanced malignancy and end stage organ failure.

program. It is essential to note that the $\mathrm{RC}$ program has not been compared with other international programs (18). However, other types of ACP programs in large health systems that target specific disease groups (19) or settings, for example the nursing homes or institutions have been studied $(20,21)$.

To understand ACP as a dynamic process, it should be regarded as a very important aspect of the ACP implementation (22). The aim of the ACP is not just to search the values and preferences of the patient in order to make a care plan for his/her future (in case the person can no longer decide for him or herself), but also to foster a change in the culture of the healthcare system currently, so that every patient can have a feeling of being listened and respected for their beliefs and preferences (23). The main axis of the ACP is to change the culture of healthcare delivery. This would imply the need for a multi-level system which involve almost all the people in the society. As such, we should focus on proper training and education as to promulgate the engagement of the ACP among different parties (healthcare staff, patients and family members). In this context, a key to have successful implementation of the
ACP program is to develop good training programs with focus on communication skills and decision-making. In fact, majority of the international ACP programs have developed certain types of training adapted to different levels of professionals (24). Our current model is a systematic process which begins with training of the frontline staff, followed by program implementation, documentation of wish items and the coordination among different medical units in a local hospital. The main outcomes of ACP programs are positive in terms of improving awareness of the ACP in our hospital, concordance with EOL wishes, and understanding of EOL preferences. One study by Weathers stated that "more discussions regarding EOL care would take place as a result of ACP interventions (25)".

Our study is limited by its retrospective design and a relatively small proportion $(\sim 17 \%)$ of patients with noncancer diagnosis. Difficulty in predicting the disease trajectories for these patients with end-stage organ failure who opted for conservative treatment and lack of simple referral methods present substantial challenge in initiating ACP discussion in these subjects (26). Although the intervention resulted in an increase in ACP document 
completion, not all targeted patients agreed to join the ACP program. As such, future studies should be conducted to explore the reasons why advanced medical illness patients decline to participate in ACP, despite being provided with the resources to do so.

Last but not least, we believe that leading healthcare and social institutions are responsible to promulgate and lead the change, and these institutions should assist and facilitate to implement the ACP at different levels. Though proper training is essential, it is not adequate; we need to develop care models which facilitate the development of ACP, to promote coordination, to develop tools (e.g., information technology) to collect the data for the ACP and make it available to our patients as well as the healthcare staff. Indicators should also be developed in order to secure the optimal ACP implementation (18).

\section{Conclusions}

Proper training to frontline staff and a collaborative approach between different subspecialties and palliative specialists can facilitate the implementation of a structured ACP program. Such structured ACP program can achieve high compliance rates to patients' final wishes and reduce overall healthcare utilization.

\section{Acknowledgments}

The authors would like to thank all medical and nursing staff in Grantham Hospital for their advice and support in our ACP program. We must also thank Dr. Theresa Lai for her help to our program.

Funding: None.

\section{Footnote}

Reporting Checklist: The authors have completed the STROBE reporting checklist. Available at http://dx.doi. org/10.21037/apm-20-589

Data Sharing Statement: Available at http://dx.doi. org/10.21037/apm-20-589

Conflicts of Interest: All authors have completed the ICMJE uniform disclosure form (available at http://dx.doi. org/10.21037/apm-20-589). KYC serves as an unpaid editorial board member of Annals of Palliative Medicine from Jul 2019 to Jun 2021. The other authors have no conflicts of interest to declare.

Ethical Statement: The authors are accountable for all aspects of the work in ensuring that questions related to the accuracy or integrity of any part of the work are appropriately investigated and resolved. Written informed consent was obtained from all participants. They were permitted to withdraw from the study at any time without negative consequences. The study was conducted in accordance with the Declaration of Helsinki (as revised in 2013). Ethical approval for this study was issued by the Institutional Review Board of the University of Hong Kong and Hospital Authority Hong Kong West Cluster (HKWC) (No.: UW 16-370).

Open Access Statement: This is an Open Access article distributed in accordance with the Creative Commons Attribution-NonCommercial-NoDerivs 4.0 International License (CC BY-NC-ND 4.0), which permits the noncommercial replication and distribution of the article with the strict proviso that no changes or edits are made and the original work is properly cited (including links to both the formal publication through the relevant DOI and the license). See: https://creativecommons.org/licenses/by-nc-nd/4.0/.

\section{References}

1. Hui D, Elsayem A, De la Cruz M, et al. Availability and integration of palliative care at US cancer centers. JAMA 2010;303:1054-61.

2. Pritchard RS, Fisher ES, Teno JM, et al. Influence of patient preferences and local health system characteristics on the place of death. SUPPORT Investigators. Study to Understand Prognoses and Preferences for Risks and Outcomes of Treatment. J Am Geriatr Soc 1998;46:1242-50.

3. Health, United States, 2010: With special features on death and dying. National Center for Health Statistics [on-line]. Available online: www.cdc.gov/ nchs/data/hus/ hus10.pdf

4. Teno JM, Clarridge BR, Casey V, et al. Family perspectives on end-of-life care at the last place of care. JAMA 2004;291:88-93.

5. Jenq G, Tinetti ME. Changes in end-of-life care over the past decade: More not better. JAMA 2013;309:489-90.

6. Mack JW, Cronin A, Taback N, et al. End-of-life care discussions among patients with advanced cancer: A cohort study. Ann Intern Med 2012;156:204-10. 
7. Halpern SD, Loewenstein G, Volpp KG, et al. Default options in advance directives influence how patients set goals for end-of-life care. Health Aff (Millwood) 2013;32:408-17.

8. Thomas K, Lobo B. Advance Care Planning in End of Life Care. Oxford: Oxford University Press, 2011.

9. Holman D, Sawkins N, Hockey J. Experience of use of Advance Care Planning in care homes. In: Thomas K, Lobo B, Detering K. editors. Advance Care Planning in End of Life Care. Oxford: Oxford University Press, 2011:132-47.

10. Detering KM, Hancock AD, Reade MC, et al. The impact of advance care planning on end of life care in elderly patients: Randomised controlled trial. BMJ 2010;340:c1345.

11. Higginson IJ, Sen-Gupta GJ. Place of care in advanced cancer: A qualitative systematic literature review of patient preferences. J Palliat Med 2000;3:287-300.

12. Chung RY, Wong EL, Kiang N, et al. Knowledge, Attitudes, and Preferences of Advance Decisions, End-ofLife Care, and Place of Care and Death in Hong Kong. A Population-Based Telephone Survey of 1067 Adults. J Am Med Dir Assoc 2017;18:367.e19-27.

13. Cheung KC, Lau VW, Un KC, et al. Advance care planning for patients with advanced neurology diseases. Ann Palliat Med 2018;7:349-54.

14. Respecting Choices: Advance Care Planning. Gundersen Lutheran Medical Foundation [on-line]. Available online: http://www.gundersenhealth.org/respecting-choices

15. Chan KY. Integrated Palliative Care Service. HA conventiion 2019. Available online: https:// haconvention2019.dryfta.com/speakers-en/abstract/ public/1363/integrated-palliative-care-for-hematologycancer-patients-how-early-is-early

16. Chan KY, Yip T, Yap DY, et al. Enhanced PsychoSocial Support for Caregiver Burden for Patients with Chronic Kidney Failure Not To Be Treated by Dialysis or Transplantation: A Pilot Randomized Controlled Trial. Am J Kidney Dis 2016;67:585-92.

Cite this article as: Chan KY, Chiu HY, Yap DYH, Li CW, Yip T, Tsang KW, Tam WO, Au HY, Wong CY, Chan ML, Sham MK. Impact of structured advance care planning program on patients' wish items and healthcare utilization. Ann Palliat Med 2021;10(2):1421-1430. doi: 10.21037/apm-20-589
17. Thomas K, Noble B. Improving the delivery of palliative care in general practice: an evaluation of the first phase of the Gold Standards Framework. Palliat Med 2007;21:49-53.

18. MacKenzie MA, Smith-Howell E, Bomba PA, et al. Respecting Choices and Related Models of Advance Care Planning: A Systematic Review of Published Evidence. Am J Hosp Palliat Care 2018;35:897-907.

19. Biondo PD, Lee LD, Davison SN, et al. How healthcare systems evaluate their advance care planning initiatives: Results from a systematic review. Palliat Med 2016;30:720-9.

20. In der Schmitten J, Rothärmel S, Mellert C, et al. A complex regional intervention to implement advance care planning in one town's nursing homes: Protocol of a controlled inter-regional study. BMC Health Serv Res 2011;11:14.

21. Overbeek A, Korfage IJ, Jabbarian LJ, et al. Advance Care Planning in Frail Older Adults: A Cluster Randomized Controlled Trial. J Am Geriatr Soc 2018;66:1089-95.

22. Fried TR, Bullock K, Iannone L, et al. Understanding advance care planning as a process of health behavior change. J Am Geriatr Soc 2009;57:1547-55.

23. Sudore RL, Lum HD, You JJ, et al. Defining Advance Care Planning for Adults: A Consensus Definition From a Multidisciplinary Delphi Panel. J Pain Symptom Manage 2017;53:821-32.e1.

24. Duckworth S and Thompson A. Evaluation of the Advance Care Planning Programme. The Health Quality \& Safety Commission and Health Workforce New Zealand: Litmus. 2017. Available online: https://www.hqsc.ovt.nz/assets/ ACP/PR/ACP_final_evaluation_report_290317.pdf

25. Weathers E, O'Caoimh R, Cornally N, et al. Advance care planning: A systematic review of randomised controlled trials conducted with older adults. Maturitas 2016;91:101-9.

26. Chan KY, Yap DYH, Yip T, et al. Palliative Care Consultation in Advanced Chronic Kidney Disease with Pain. J Palliat Med 2018;21:809-14. 